\title{
Elastic band ligation for the removal of a colonic tubular adenoma in a diverticulum
}

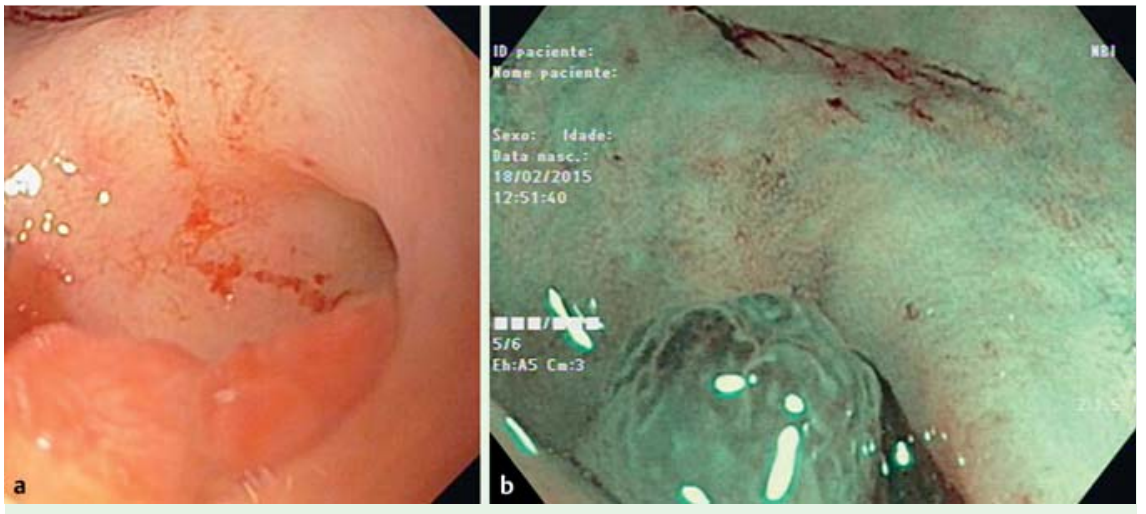

Fig. 1 a Sessile polyp in the neck of a diverticulum with intradiverticular extension, seen in a 56-yearold healthy patient undergoing colonoscopy after a positive fecal occult blood test result. b Narrowband imaging shows a large tubular pit pattern.

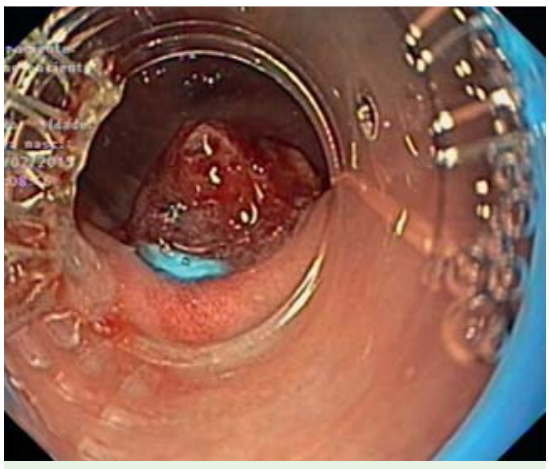

Fig. 2 The polyp is visible on the top of the inverted diverticulum.

A 56-year-old healthy patient underwent colonoscopy after a positive fecal occult blood test result. This examination showed diverticulosis of the left side of the colon and, at $20 \mathrm{~cm}$ from the anal verge, a 6-mm sessile polyp in the neck of a diverticulum with intradiverticular extension ( $\bullet$ Fig. 1 a). Narrow-band imaging showed a large tubular pit pattern: Kudo type III-L ( $\bullet$ Fig. 1 b).

Using a gastroscope (GIF-Q165; Olympus, Tokyo, Japan) with a conventional band ligator device (Speedband Superview Super; Boston Scientific, Natick, Massachusetts, USA) attached to the tip, we positioned the diverticular orifice and the polyp in the center of the cap. The diverticulum (including the insertion area of the polyp) was then suctioned and partially inverted into the cap of the endoscopic ligator, and an elastic band was re-

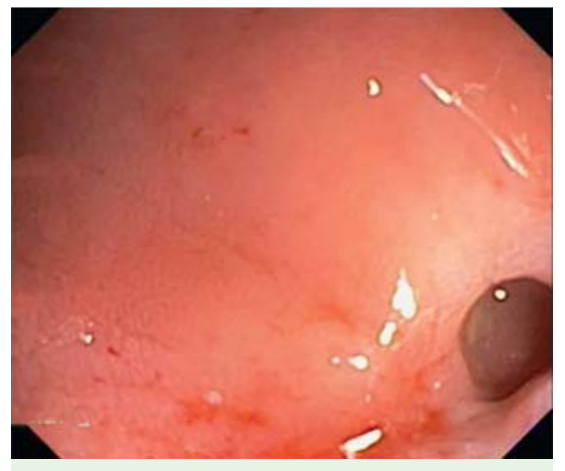

Fig. 3 After 2 weeks, a cicatricial area is identified on the neck of the residual diverticulum, with no evidence of residual adenoma.

leased around its neck ( Video 1 ). The polyp was visible on the top of the inverted diverticulum ( $\bullet$ Fig.2). Colonic tattooing was performed.

As a result of ischemia, necrosis, and cicatrization of the underlying tissues, the elastic band contents fell off in a few days [1]. Endoscopic evaluation 2 weeks later showed a residual diverticulum adjacent to the tattoo. A cicatricial area was identified on the neck of the residual diverticulum, with no evidence of residual adenoma ( $\bullet$ Fig. 3).

Colonic diverticula do not have a muscular layer, so there is a high risk for perforation when a standard snare excision technique is used for polyps extending into diverticula. Elastic banding has recently been shown to be safe and highly effective in diverticular bleeding [2]. It appears that this technique may also be safe and effec-

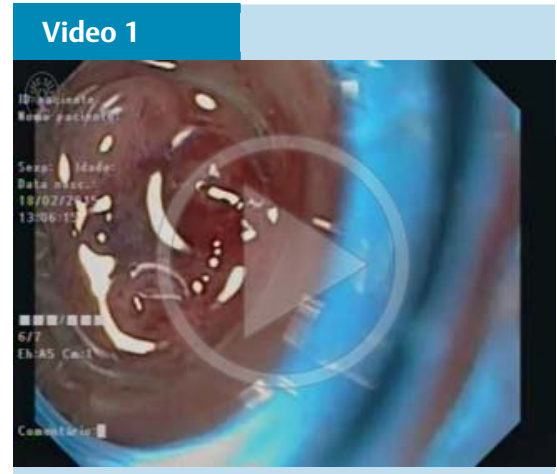

Elastic band ligation for the removal of a colonic tubular adenoma in a diverticulum.

tive for the resection of a colonic adenoma extending into a diverticulum [3]. It is also minimally invasive, so that perforation and the need to perform laparoscopy or apply an over-the-scope-clip to close it can be avoided [4,5]. However, no specimen is obtained for histopathological analysis, which probably limits the size and the pit pattern of the polyps in which this technique should be used.

\section{Endoscopy_UCTN_Code_TTT_1AQ_2AD}

Competing interests: None

\section{Joana Carmo, Susana Marques, Iolanda Chapim, Pedro Barreiro, Miguel Bispo, Cristina Chagas}

Gastroenterology Department, Hospital Egas Moniz, Centro Hospitalar de Lisboa Ocidental, Lisboa, Portugal

\section{References}

1 Akimaru K, Suzuki H, Tsuruta $H$ et al. Eversion and ligation of a diverticulum: report of an inspirational case and subsequent animal study. J Nippon Med Sch 2008; 75 : 157-161

2 Ishii $N$, Setoyama $T$, Deshpande GA et al. Endoscopic band ligation for diverticular hemorrhage. Gastrointest Endosc 2012; 75 : 382-387

3 Barker KB, Arnold HL, Fillman EP et al. Safety of band ligator use in the small bowel and the colon. Gastrointest Endosc 2005; 62: 224-227 
4 Fu KI, Hamahata Y, Tsujinaka Y. Early colon cancer within a diverticulum treated by magnifying chromoendoscopy and laparoscopy. World J Gastroenterol 2010; 16: $1545-1547$

5 Valli PV, Kaufmann M, Vrugt B et al. Endoscopic resection of a diverticulum-arisen colonic adenoma using a full-thickness reception device. Gastroenterology 2014; 147 : 969-971
Bibliography

Dol http://dx.doi.org/

10.1055/s-0034-1393142

Endoscopy 2015; 47: E490-E491

(c) Georg Thieme Verlag KG

Stuttgart · New York

ISSN 0013-726X

\section{Corresponding author}

Joana Carmo, MD

Gastroenterology Department Hospital Egas Moniz

Centro Hospitalar de Lisboa Ocidental

Rua da Junqueira, 126

1349-019 Lisbon

Portugal

Fax: +351-213624139

joanavcarmo@gmail.com 